\title{
Diacronie
}

Studi di Storia Contemporanea

$\mathrm{N}^{\circ} 24,4 \mid 2015$

Le dittature militari: fisionomia ed eredità politica

\section{Arrepentimendos, olvidos y silencios. Nueva lectura del apoyo periodistico al Golpe de estado de 1964 en Brasil}

Julio Héctor Macías

\section{(2) OpenEdition \\ Journals}

Edición electrónica

URL: http://journals.openedition.org/diacronie/3757

DOI: $10.4000 /$ diacronie.3757

ISSN: 2038-0925

Editor

Association culturelle Diacronie

Referencia electrónica

Julio Héctor Macías, « Arrepentimendos, olvidos y silencios. Nueva lectura del apoyo periodistico al Golpe de estado de 1964 en Brasil », Diacronie [En línea], № 24, 4| 2015, documento 11, Puesto en línea el 29 diciembre 2015, consultado el 19 abril 2019. URL : http://journals.openedition.org/ diacronie/3757 ; DOI : 10.4000/diacronie.3757 


\title{
Diacronie
}

\section{1/}

\section{Arrepentimientos, olvidos y silencios. Nueva lectura del apoyo periodístico al golpe de estado de 1964 en Brasil}

\author{
Julio Héctor MACÍAS *
}

En 2013, el diario «O Globo» de Brasil reconoció como un "error histórico" haber apoyado la destitución en 1964 del presidente constitucional brasileño João Goulart. En su viaje al pasado O Globo incorporó a varios compañeros de ruta, como otros diarios, además de recordar el apoyo que una parte de la sociedad brasileña le brindó a la intervención militar. ¿Qué llevó a un medio aún poderoso e influyente a reconocer como equivocada una posición asumida hace cincuenta años? Buscamos recrear las principales argumentaciones a favor del golpe de los sectores más enfrentados a Goulart y visibilizar cómo contribuyeron a la formación de una nueva alianza de los sectores dominantes, que pronto mostró sus límites.

\author{
Mais uma vez \\ o povo brasileiro \\ foi socorrido \\ pela Providéncia Divina \\ [...] Sejamos dignos \\ de tão grande favor ${ }^{1}$.
}

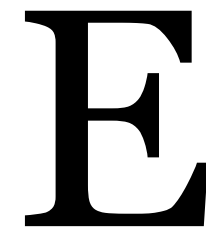

n agosto de 2013, el diario «O Globo» de Río de Janeiro reconoció que fue un "error histórico" haber apoyado en 1964 la destitución del presidente constitucional brasileño João Goulart:

\footnotetext{
${ }^{1}$ Párrafo final del editorial «Ressurge a Democracia!», publicado por el diario $O$ Globo el 2 de abril de 1964, una vez producido el derrocamiento del presidente constitucional João Goulart.
} 
A lembrança é sempre um incômodo para o jornal, mas não há como refutá-la. É História. «O Globo», de fato, à época, concordou com a intervenção dos militares, ao lado de outros grandes jornais, como «O Estado de S.Paulo», «Folha de S. Paulo», «Jornal do Brasil» e o «Correio da Manhã», para citar apenas alguns. Fez o mesmo parcela importante da população, um apoio expresso em manifestações e passeatas organizadas em Rio, São Paulo e outras capitais² .

Las Fuerzas Armadas brasileñas instauraron en 1964 lo que Ansaldi3 considera la primera dictadura institucional en el Cono Sur sudamericano, por la cantidad de normas sancionadas para asegurar la sucesión y continuidad en el ejercicio del gobierno y cuyo basamento ideológico puede sintetizarse en la idea del Estado burocrático-autoritario ${ }^{4}$. El golpe contra el Presidente Goulart depositó en el poder al general Humberto de Alencar Castelo Branco, hasta entonces Jefe del Estado Mayor del Ejército.

El nuevo presidente asumió con facultades que correspondían al Poder Legislativo y un poder más centralizado y concentrado en el Ejecutivo, en procura de «reconstruir la economía, la política y la moral» brasileñas y «restaurar el orden» y jerarquía internas, puestas en peligro por un gobierno que pretendía "bolchevizar" al país, según decía El Acta Institucional Nro. 1 sancionada el 9 de abril de 1964, menos de dos semanas después del golpe. En este trabajo analizaremos el soporte brindado por varios de los más importantes diarios brasileños al golpe de 1964 contra el presidente Goulart, algo que los estudios académicos, tanto dentro como fuera de Brasil han tratado y considerado desde variados puntos de abordaje ${ }^{5}$.

2 «Apoio editorial ao golpe de 64 foi um erro», in $O$ Globo, 31 de agosto de 2013.

3 ANSALDI, Waldo, GIORDANO, Verónica, América Latina. La construcción del orden, t. II, Buenos Aires, Ariel, 2012, pp. 409-412.

4 O'DONNELL, Guillermo, El Estado burocrático-autoritario. Triunfos, derrotas y crisis, Buenos Aires, Editorial de Belgrano, 1982, pp. 157-160.

5 Entre los trabajos más recientes que incluyen, a su vez, detallados estados de la cuestión y sin pretensión de ser exhaustivos conviene señalar a ANSALDI, Waldo, GIORDANO, Verónica, op. cit., tt. I, II; RAMÍREZ, Hernán, «El golpe de Estado de 1964 en Brasil desde una perspectiva socio política», in PolHis, 9, 2012, pp. 255-266, URL:

< http://historiapolitica.com/datos/boletin/Polhis9_RAMIREZ.pdf > [consultado el 3 de septiembre de 2013]; ALVES DA SILVA, Ionio, "Columna de Castello: la opinión en el periodismo brasileño y el golpe militar de 1964", in Perspectivas de la comunicación, 5, 2/2012, pp. 74-88, URL: < http://dialnet.unirioja.es/servlet/articulo?codigo $=4221998>$ [consultado el 3 de septiembre de 2013]; VITALE, María Alejandra, «Sentidos de "revolução" y "revolución" en la prensa escrita golpista de Brasil (1964) y de Argentina (1966)», in Bakhtiniana. Revista de estudos do discurso em formato electrônico, 8, 1/2013, pp. 254-274, URL: < http://www.scielo.br/pdf/bak/v8n1/es_a16v8n1.pdf > [consultado el 3 de septiembre de 2013]; BONSANTO DIAS, André, «<64 - Brasil continua $>$ : História, memória e as impressoes da Folha de S. Paulo sobre o golpe militar de 1964", in Revista Brasileira de História da Mídia (RBHM), 2, 1/2013, pp. 49-59, URL < http://www.unicentro.br/rbhm/edo3/dossie/o5.pdf > [consultado el 3 de septiembre de 2013]. 
El rol del periodista como intelectual orgánico que opera, especialmente, en el interior de la sociedad civil y que sirve a la hegemonía de un grupo social sobre el resto de la sociedad nacional a través de determinadas organizaciones, una de las cuales es la prensa $^{6}$ ha sido suficientemente analizado y explorado por las ciencias sociales. A la luz del "mea culpa" del principal emporio periodístico de Brasil el objetivo del presente estudio es revisitar las argumentaciones que desplegaron determinados diarios brasileños en la época del gobierno de Goulart (1961-64), cómo intervinieron en el conflicto institucional que terminó con su deposición y qué rol tuvieron en su caída. Es decir, en términos gramscianos, cómo contribuyeron a que el régimen militar pudiera poner en marcha una alianza, surgida en este caso de la fuerza de las armas, y conformar a través de una serie de compromisos (consensos) o la subordinación a partir de la coerción, un nuevo bloque histórico-económico-político de poder cuyas propias contradicciones internas pronto quedarían expuestas.

Nos enfocaremos en el análisis de las noticias suministradas por «O Globo» y las opiniones periodísticas de sus principales columnistas, pero también en las de «Jornal do Brasil» de Río de Janeiro y «Folha de São Paulo» y «O Estado de São Paulo», ambos de San Pablo (dos de las ciudades más importantes del Brasil). Adicionalmente, incorporamos informes y editoriales de «A Noite» y «Correio da Manhã» de Río de Janeiro, y «Diário da Noite» de San Pablo, para conocer qué se dijo, cómo y qué se informó. También utilizamos datos estadísticos y comentarios aparecidos en «Conjuntura Econômica» de Río de Janeiro. Pretendemos comprobar, básicamente, cuál fue el impacto que tuvieron esos medios de comunicación en los sucesos que precedieron al derrocamiento de $\operatorname{Jango}^{7}$ y entrever su grado de influencia en los primeros tiempos del régimen militar que se extendió hasta la década de los '8o. Procuramos saber de qué se arrepintió «O Globo» y si los otros medios deberían hacer lo mismo.

6 GRAMSCI, Antonio, Antología. Selección, traducción y notas de Manuel Sacristán, Buenos Aires, S. XXI, 2009, 1970, p. 272.

$7 \mathrm{El}$ sobrenombre con que popularmente se conocía a Goulart. De tal modo se lo referenciaba incluso en la prensa. 


\section{Feudos familiares y oligárquicos}

Según Beatriz Kushnir las empresas periodísticas brasileñas pueden ser vistas como feudos oligárquicos ${ }^{8}$. Los principales diarios fueron, a través de casi toda su historia, emprendimientos familiares. El 29 de julio de 1925, en los tramos finales de la República Velha, el periodista Irineu Marinho, entonces propietario del vespertino «A Noite», fundó en Río de Janeiro el matutino: «O Globo». A su muerte, poco después, su hijo mayor Roberto se hizo cargo del diario y le dio un gran impulso al desarrollo periodístico, lo que le permitió acumular poder económico e influencia políticas. En 1944 el grupo pasó a tener su propia emisora de radio y en 1964 se inauguró TV Globo9, cuyas transmisiones comenzaron un año más tarde. Hoy por hoy, la Organización Globo es un gigantesco holding de medios de comunicación, que abarca la versión papel y también el contenido digital, más varias emisoras de radio y canales de televisión en Brasil y Portugal, además de inversiones en la banca y negocios inmobiliarios.

«O Globo» forma parte, además, del “Grupo de Diarios América” (GDA), creado en 1991, y que integran otros diez diarios continentales: «La Nación» de Argentina, «El Mercurio» de Chile, «El Tiempo» de Colombia, «La Nación» de Costa Rica, «El Comercio» de Ecuador, «El Universal» de México, «El Comercio» de Perú, «El Nuevo Día» de Puerto Rico, «El País» de Uruguay y «El Nacional» de Venezuela. Son diarios de gran tradición en sus países - algunos nacidos en el siglo XIX -, todos ellos vinculados a intereses económicos y de poder. Estos medios consideran que cada uno de ellos «juega un papel clave al informar e influir en la opinión pública en sus respectivos mercados. Sus lectores son individuos altamente educados, con recursos financieros y alto poder de decisión ${ }^{10}$. Algo que une a estos a estos diarios es su pertenencia a sectores políticos conservadores. Por otro lado, en el pasado, algunos fueron vinculados a procesos de ruptura del orden democrático en sus respectivos países (por ejemplo, los apoyos de «La Nación» de Buenos Aires a varios de los golpes militares durante el siglo XX o los de «El Mercurio» de Santiago al golpe contra Salvador Allende en 1973).

\footnotetext{
8 Beatriz Kushnir lo explica en RAMÍREZ, Hernán (coords.), «Dossier. La dictadura cívico militar brasileña», 2012, p. 28, in Historiapolítica.com, disponible en URL:

$<$ http://historiapolitica.com/dossierbrasil > [consultado el 21 de septiembre de 2013].

9 En la actualidad es la segunda cadena de la TV mundial, detrás de ABC de Estados Unidos, y la primera de América Latina. Jornal do Brasil, 9 de mayo de 2012.

${ }_{10}$ Según se lee en la página web del GDA, URL < http://www.gda.com > [consultado el 5 de septiembre de 2013].
} 
«Jornal do Brasil» se publicó entre 1891 y 2010, cuando abandonó definitivamente - entre otras cosas por cuestiones económicas- la versión papel para dedicarse sólo a la versión digital. Hasta ese momento era el tercer diario más antiguo de Brasil. Lo fundaron partidarios de la monarquía brasileña, que acababa de ser sustituida por la luego llamada República Velha. Pero su posición política original se modificó con el paso del tiempo y para los '50 era considerado un medio de centroizquierda. Su línea editorial se ponía de manifiesto en las "columnas de Castello" que reflejaban los principales acontecimientos políticos y que eran escritas por el periodista Carlos Castello Branco, considerado un «organizador de enunciados» $y$ sentidos periodísticos ${ }^{11}$.

«O Globo» y «Jornal do Brasil» llevaron adelante desde octubre de 1963 y hasta abril de 1964 el programa de radio Rede da Democracia que se transmitía en horario nocturno por las emisoras de esas empresas Rádio Globo, Rádio JB y también Rádio Tupi, que pertenecía a Diários Associados - organización creada por Francisco de Assis Chateaubriand Bandeira de Mello, muy influyente en la política brasileña entre las décadas de los '30 y los '6o, que llegó a conglomerar casi cuarenta diarios, una veintena de revistas, varias decenas de emisoras de radio, unos 20 canales de TV (los primeros en Brasil) y hasta una agencia de noticias-. Los principales contenidos de Diários Associados se caracterizaron por ser contrarios al gobierno de Goulart.

«Folha de São Paulo» se fundó el 19 de febrero de 1921, en San Pablo. Primero apareció como vespertino. Su estilo periodístico se diferenciaba de los otros por su mayor agilidad en el tratamiento de las noticias y porque buscó tener independencia del poder político y que su público lector estuviera más vinculado con la clase media y con los trabajadores de zonas urbanas que con las elites políticas y económicas. A comienzos de los '6o pasó a ser matutino, al fusionarse tres diarios que pertenecían al llamado Grupo Folha. Desde 1962 su línea editorial se volvió abiertamente anti janguista y apoyó los preparativos y la concreción de la interrupción democrática de $1964^{12}$. A través de los años tuvo varios dueños y para la época del golpe contra Goulart, sus propietarios eran Octavio Frias de Oliveira y Carlos Caldeira Filho. Su opinión editorial aparecía en la página 4, bajo el eslógan oficial: «un diario al servicio de Brasil». Hacia los '70 amplió su presencia en los medios de comunicación con la adquisición de varias emisoras de radio, al mismo tiempo que fue el blanco de varios atentados de grupos de ultraizquierda que acusaban a "Folha..." de colaborar con la dictadura. En la actualidad, además de ser el diario más vendido de Brasil, el Grupo

\footnotetext{
${ }^{11}$ ALVES DA SILVA, Ionio, op. cit., p. 80.

12 KUSHNIR, Beatriz, op. cit., p. 29.
} 
Folha es un conglomerado que controla el mayor portal de Internet de ese país (UOL), otros periódicos en San Pablo, un centro de estudios y encuestas, editoriales y sellos discográficos.

«O Estado de São Paulo» fue fundado el 4 de enero de 1875 por republicanos integrantes de una de las familias más influyentes del periodismo brasileña: los Mesquita. Primero fue «A Provincia de S. Paulo» nombre que cambió a fines de 1889, ya caída la monarquía y establecida la República Velha. Siempre representó los intereses de las elites rurales (sobre todo paulistas) y asumía una posición conservadora en lo político y liberal en lo económico, una postura más bien tradicional. Saludó el triunfo de la Revolución de octubre de 1930 que puso en el poder a Vargas ${ }^{13}$, pero en 1932 apoyó el levantamiento de los llamados constitucionalistas paulistas contra el propio Vargas, quien intervino el diario entre 1940 y 1945. «O Estado de São Paulo» era férreo opositor al Estado Novo varguista. A fines de los '50 y principios de los '6o, el diario apoyó a la UDN de Carlos Lacerda ${ }^{14}$ que luego fue gobernador de Guanabara y cuando asumió Goulart se manifestó abiertamente en contra de su gobierno. La postura editorial del diario aparecía siempre en la página 3 bajo el título «Notas e Informaciones». En la actualidad, el holding de «O Estado de São Paulo» abarca diarios, emisoras de radio de AM y FM, sitios de internet y una agencia de noticias.

«Correio da Manhã» se publicó en Río de Janeiro de 1901 a 1974 y fue fundado por los hermanos Edmundo y Paulo Bittencourt. Fue uno de los más críticos de Goulart y sus editoriales de los días inmediatamente anteriores y posteriores al golpe son tajantes en cuanto a su posicionamiento a favor del golpe. «A Noite» de Río de Janeiro estaba dirigido por Antonio Vieira de Mello y «Diário da Noite», de San Pablo, integraban la organización Diários Associados. Conjuntura Econômica es una publicación mensual (vigente), muy influyente en los sectores de decisión económica y política.

\footnotetext{
${ }^{13}$ En octubre de 1930 Getúlio Vargas encabezó una Revolución que Ansaldi califica de política y que fue la expresión del descontento de sectores de la oligarquía durante la Republica Velha. Vargas fue presidente provisorio hasta 1934, presidente constitucional de 1934 a 1937, dictador durante el Estado Novo entre 1937 y 1945 y luego presidente constitucional entre 1951 y 1954, cuando se suicidó y le dijo póstumamente al pueblo brasileño que dejaba "la vida para entrar en la historia”. Goulart era uno de sus ministros más próximos y se desempeñaba al frente de la cartera de Trabajo. Ansaldi entiende que el populismo brasileño se extiende desde 1951 a 1964, o sea desde la última presidencia de Vargas hasta el fin del gobierno de Goulart, con una fase desarrollista entre 1955 y 1960. Ver $O$ Globo 24 de agosto de 1954 y, entre otros, ANSALDI, Waldo, GIORDANO, Verónica, op. cit, t. I, especialmente p. 582.

14 Lacerda era periodista y en su juventud estuvo vinculado al Partido Comunista brasileño, que lo expulsó en 1938 acusándolo de traidor. Lacerda se volvió un acérrimo anticomunista. También combatió al varguismo.
} 


\section{El DGI durante el Proceso de Reorganización Nacional}

«Jornal do Brasil» saludó con esperanza la asunción de Jânio Quadros como presidente brasileño, luego del periodo de Juscelino Kubitschek, y se aguardaba de su gestión que concretara la esperanza que se había despertado en él para avanzar por los caminos de justicia, progreso, paz política y social:

O Sr. Jânio Quadros toma posse hoje na Presidência da República, no cumprimento do mais expressivo mandato popular jamais recebido por um político brasileiro. Do Sr. Jânio Quadros ninguém espera que faça apenas um Governo bom, mas excelente. Trata-se do primeiro candidato oposicionista a subir ao Poder, em toda a história da República, depois de enfrentar uma coalizão de forças governistas. Veio tirar do Poder grupos políticos que o dominavam desde 1930. E venceu com uma vantagem de quase dois milhões de votos sobre o seu principal adversário $[\ldots]^{15}$.

Por el peculiar sistema electoral brasileño, que permitía sufragar con boletas separadas para presidente y vice, le tocó a João Goulart (que había acompañado a Kubitschek en la fórmula presidencial que se impuso en las elecciones de 1955) asumir como segundo de Quadros, cuando éste ganó las presidenciales de 1960, a pesar de ser de coaliciones políticas opuestas (Quadros era de la UDN, Unión Democrática Nacional, y Goulart del PTB, Partido Trabalhista Brasileño).

La presidencia de Quadros fue breve, ya que renunció a fines de agosto de 1961. Su mandato estuvo marcado por la intención de aproximación a Unión Soviética y China, entonces faros del comunismo mundial junto con Cuba, país al que se apoyó en contra de la voluntad de Estados Unidos de expulsar al régimen castrista de la OEA (Organización de Estados Americanos), lo que finalmente ocurrió. Eso sin contar algunas otras decisiones polémicas sobre temas más mundanos.

Cuando renunció Quadros, su vice Goulart estaba de visita oficial en China. Eso permitió el brevísimo interinato del presidente de la Cámara de Diputados Ranieri Mazzilli. Los ministros militares y sectores considerados anticomunistas, apoyados por miembros del bloque histórico de poder, fueron renuentes a aceptar la asunción de Goulart.

La salida que se encontró a la situación, dos semanas más tarde, fue una enmienda a la Constitución, que habilitaba la transferencia de parte del poder del Ejecutivo al

15 Jornal do Brasil, 1 de febrero de 1961. 
Congreso, que a través de la figura del Primer Ministro ${ }^{16}$ controlaría las actidades del Presidente. La debilidad presidencial, el recorte evidente de sus facultades constitucionales, no pudo ser modificada a pesar de los apoyos sociales que recibió de algunos políticos, como Leonel Brízola - su cuñado -, diputado por Río Grande do Sul, varios sindicatos, también de partidos de izquierda y grupos minúsculos dentro del Ejército, la Marina y la Iglesia católica ${ }^{17}$. Las presiones de sectores ubicados más a la derecha del espectro político brasileño eran más fuertes, aunque no habían sido capaces de articular una alternativa electoral que los aglutinara eficazmente. Eran dominantes pero no hegemónicos ${ }^{18}$. Sin embargo, la crisis iniciada en agosto de 1961 será el preámbulo del golpe de marzo de 1964.

A lo largo de 1962, Goulart se apoyó en las huelgas convocadas por sindicatos afines en los que prevalecían comunistas y trabajadores de izquierda ${ }^{19}$ para presionar al Congreso en la búsqueda de retornar al presidencialismo y recuperar el ejercicio pleno del poder, a través de un plebiscito ${ }^{20}$. A principios de julio de ese año, el Parlamento designó - por amplia mayoría: 222 votos a 51- al senador Auro de Moura Andrade, enfrentado con Goulart, como primer ministro con lo cual la situación se retensó. Andrade renunció tres días después y fue reemplazado por Francisco Brochado da Rocha, quien asumió sin el apoyo de los partidos políticos. El 5 de julio hubo una huelga nacional, que desembocó - en Río de Janeiro - en centenares de saqueos, con un saldo de una veintena de muertos y mil heridos ${ }^{21}$. Goulart quería que el plebiscito para el retorno al presidencialismo fuera en octubre, pero finalmente se desarrolló el 6 de enero de 1963.

\footnotetext{
${ }_{16} \mathrm{Al}$ inaugurarse la etapa del parlamentarismo brasileño, en 1961, el Primer Ministro fue Tancredo Neves, quien años más tarde, en 1985, sería elegido presidente democráticamente, aunque no pudo asumir porque murió antes de hacerlo.

17 RAMÍREZ, Hernán, «El golpe de Estado de 1964 en Brasil desde una perspectiva socio política», cit., p. 257.

${ }^{18}$ Ibidem, p. 258.

19 Véase: BEZERRA DE MELO, Demian, «Crise orgânica e ação política da classe trabalhadora brasileira: a primeira greve geral nacional (5 de julho de 1962)», Tesis Doctoral en Historia, Universidad Federal Fluminense, Rio de Janeiro, 2013.

20 DEMIER, Felipe Alexandre, «Legalistas e golpistas contra os trabalhadores. A Inflexao política do legalismo militar sob o governo Goulart (1961-1964)», in XXIII Simpósio Nacional de História, Londrina, 2005, p. 7, URL: < http://anpuh.org/anais/wpcontent/uploads/mp/pdf/ANPUH.S23.0356.pdf > [consultado 11 de septiembre de 2013].

${ }^{21}$ BEZERRA DE MELO, Demian, op. cit.
} 


\section{La vuelta al presidencialismo}

Goulart logró finalmente, a través de un plebiscito, derogar el parlamentarismo y retornar al presidencialismo. Tuvo éxito electoral. Sobre un total de 18 millones de brasileños en condición de votar lo hicieron unos 12 millones, de los cuales casi 9 millones y medio optaron por el presidencialismo y poco más de 2 millones votaron a favor de mantener el parlamentarismo. La abstención fue de casi el 38 por ciento. Rápidamente, los sectores de la prensa más enfrentados con el presidente procuraron licuar, minimizar, ridiculizar o descalificar el resultado del plebiscito e incluso alentaron la conformación de un frente nacional de oposición para enfrentar «las soluciones discrecionales del gobierno ${ }^{22}$. Lo que ocurrió fue que, a partir de ese momento, Goulart inició un proceso político que sus adversarios entendieron como una radicalización, en tiempos de Guerra Fría y Doctrina de la Seguridad Nacional, en los cuales el éxito de la Revolución Cubana de 1959 era una señal de alarma para los grupos dominantes. A fines de marzo de 1963, Río de Janeiro fue la sede de un "Congreso continental de solidaridad con Cuba”, que el gobernador Lacerda pretendió impedir, lo que originó una minicrisis y tensión con el gobierno federal. Fue allí que Luis Carlos Prestes habló de un «Brasil cubano»23.

Según la opinión de «O Estado de São Paulo» «al regresar el presidencialismo se sucedieron una serie ininterrumpida de crisis y agitaciones, estimuladas por el propio Presidente de la República [...] bajo el pretexto de la reforma agraria, el voto de los analfabetos y una imprecisa reforma política» ${ }^{24}$ y mencionaba las actitudes populistas de Goulart, los atentados contra el gobernador Lacerda y el frustrado motín de los

22 «Jango forte de apoio popular e fraco de apoio politico», in Jornal do Brasil, 8 de enero de 1963; O Estado de São Paulo, 9 de enero de 1963. Este diario definió a la votación como una "farsa".

${ }_{23}$ Jornal do Brasil, 30 de marzo de 1963. Luis Carlos Prestes era un histórico líder tenentista y dirigente comunista. Los tenentes (o movimiento tenentista) ì fueron un grupo de oficiales rebeldes del Ejército durante la llamada Republica Velha, entre ellos Humberto de Castelo Branco, Ernesto Garrastazú Médici o Ernesto Geisel (que serían presidentes después de 1964), los que comenzaron una insurrección en 1922 que no contó con otros apoyos y fue derrotada por las fuerzas leales a la dominación oligárquica. Lo intentaron nuevamente en 1924 y volvieron a fracasar, pero una expedición encabezada por uno de sus líderes, conocida como "columna Prestes" recorrió 20 mil kilómetros del territorio brasileño en búsqueda de respaldo. En 1926 volvieron a plantear una rebelión militar que también fue vencida. Ver entre otros, ANSALDI, Waldo, GIORDANO, Verónica, op. cit, t. I. En 1935 Prestes intentó una insurrección comunista, ferozmente reprimida por Vargas y terminó preso por varios años. Durante el mes de marzo de 1964, en casi todos los periódicos y de manera diaria, aparecían referencias a dichos o acciones de Prestes.

${ }_{24}$ O Estado de São Paulo, 1 de enero de 1964. 
sargentos de la Marina y Aeronáutica en setiembre de 1963, lo que para el diario marcaba la indisciplina y deterioro de la autoridad en las Fuerzas Armadas.

Las continuas huelgas que se registraban en distintos ámbitos sindicales le impedían al Presidente Goulart tener la situación bajo control. El 12 de septiembre de 1963 se conoció que el Tribunal Superior de Brasil había considerado que los sargentos no podían ser elegibles para cargos políticos estaduales. Ese mismo día unos 650 sargentos, cabos y soldados tanto de la Marina (fuzileiros) como de la Aeronáutica, con la excusa de reclamar la elegibilidad para cargos políticos de oficiales de bajo rango, llevaron adelante por espacio de 9 horas una insurrección armada contra las autoridades de sus fuerza durante la cual ocuparon el Ministerio de Marina y otros edificios federales. La intervención del Ejército para poner en caja a los rebeldes se zanjó con 2 muertos. Los amotinados no fueron sancionados.

Las cúpulas militares observaban con preocupación el clima de potencial quiebre de la jerarquía interna en las Fuerzas Armadas y el riesgo cierto de caer en lo que más temían: su "bolchevización". Las tres fuerzas, sobre todo el Ejército, siempre habían visto con desconfianza a Goulart y su gobierno. Mientras desde el sector político más cercano al Presidente se buscó concretar las reformas y modificaciones sociales que entendían indispensables para el proyecto que llevaban adelante, los grupos militares y los factores de poder económicos y sociales enfrentados con el Ejecutivo -entre los que, claro, figuraban los principales diarios-, se dedicaron en los siguientes seis meses, hasta marzo de 1964, a armar la estructura que necesitaban para forzar la caída del régimen constitucional, para lo que una de las argumentaciones fue que era necesario defender «la democracia en peligro» 25 .

\section{El Club Militar}

El Club Militar de Brasil no era en la década de los años '6o (tampoco hoy) un lugar sólo de sociabilidad de la oficialidad activa o en retiro. Uno de sus objetivos principales era el estrechar los lazos de unión y solidaridad entre los oficiales de las tres Fuerzas Armadas, pero también incentivar y promover manifestaciones democráticas y patrióticas. Desarrollaba tareas asistencias, sociales y culturales. Funcionaba como una entidad de intermediación entre las Fuerzas Armadas y el poder político del país. Una

25 Ése es el título del artículo sobre los años del gobierno de Goulart en la web del Club Militar que ha sido una de las fuentes para el siguiente apartado; véase: «Democracia em perigo», Clube Militar. A casa da República, URL: < http://clubemilitar.com.br/nossa-historia/democraciaem-perigo/ > [consultado el 27 de septiembre de 2015]. 
de sus tareas primordiales era la gremial, por lo que quien estuviera a su frente adquiría un rol de gestión preponderante, y si bien trataba de permanecer al margen de las disputas políticas varios de sus miembros intervinieran directa o indirectamente en cuestiones de ese tipo.

En mayo de 1962, menos de un año después de haber asumido Jango, el Club Militar llevó adelante su habitual proceso bianual de elecciones internas. Los candidatos eran el general Per Constant Beviláqua y el general Augusto da Cunha Magessi. Peri se había definido así mismo como «legalista los días pares e impares» y un «nacionalista democrático» ${ }^{26}$. La plataforma de Magessi se basaba en evitar la discordia al interior de la fuerza militar ya que él era «contrario a cualquier vinculación política o doctrinaria» ${ }^{27}$.

Peri se impuso en casi todas las guarniciones del interior brasileño y parecía encaminarse hacia su proclamación como nuevo jefe del organismo militar, lo que hubiera representado un apoyo no menor para el presidente Goulart. Sin embargo, Magessi ganó en Minas Gerais, San Pablo y en los distritos claves de Guanabara y Niterói, con lo cual terminó por imponerse en una elección que registró una altísima abstención de casi un 60 por ciento ${ }^{28}$. Hubo impugnaciones cruzadas y en algún momento se pensó en anular las elecciones. Hasta llegó a denunciarse un fraude, atribuido a partidarios de Magessi ${ }^{29}$. Sin embargo, la Junta Electoral que estaba integrada por personal militar que simpatizaba con la candidatura de Magessi confirmó el triunfo de éste, que sumó los respaldos de oficiales muy influyentes como el mariscal y expresidente Eurico Gaspar Dutra y los generales Artur da Costa e Silva que luego fue presidente durante la dictadura - y Amaury Kruel.

Pocos meses después, en setiembre de 1962, Peri quedó a cargo del II Cuepo de Ejército y en un giro sorprendente se aproximó a la influyente burguesía industrial paulista y terminó por convertirse en «enemigo intransigente» de los trabajadores y el sindicalismo, que antes apoyaba ${ }^{30}$. A fines de 1963, Goulart lo destituyó y en su lugar asumió el general Kruel. Durante su mandato de dos años, la relación de Magessi con

${ }^{26}$ Diário da Noite, 3 de enero de 1962.

27 Diário da Noite, 4 de enero de 1962.

${ }^{28}$ Jornal do Brasil, 17 y y 18 de mayo de 1962. Los distritos donde ganó Magessi dos años más tarde serían los más activos en el golpe contra Goulart.

29 Jornal do Brasil, 19 de mayo de 1962; «Fraude nas eleiçoes para direçao do Clube Militar», in A Noite, 25 de mayo de 1962. Este diario publicó en sus ediciones subsiguientes más informaciones y "pruebas" del supuesto fraude, hasta que, pocos días después y de modo sorpresivo, abandonó sus denuncias y en un sobrio recuadro en su tapa sólo informó que «el general Magessi, electo en el Club Militar, divulga su plan administrativo». Cfr. A Noite, 2 de junio de 1962.

3o DEMIER, Felipe Alexandre, op. cit., p. 4. 
Goulart fue formal y distante. El Club Militar se alejó cada vez más de las posiciones del oficialismo, que consideraba "izquierdizantes", sobre todo a partir de la insurrección de los sargentos y fuzileiros de septiembre de 1963. Al repetirse ésta en marzo, el Club Militar no dudó en manifestar su oposición al gobierno (ver más adelante) e incluso en la jornada del golpe, grupos de manifestantes pro-Goulart intentaron ocupar sus instalaciones, pero fueron reprimidos por tropas del Ejército, que intervinieron a pedido de Magessi.

\section{Reformas de base y situación económica}

El año 1964 se inició con la manifiesta «desconfianza» de varios de los principales medios de comunicación masiva acerca de «las verdaderas intenciones de Goulart» sobre todo en torno de la reforma constitucional, para lo cual se basaban en el mensaje de fin de año del propio mandatario que había dicho que «el poder económico no puede continuar interfiriendo a la voluntad del pueblo expresada en las urnas» ${ }^{31}$. Por otro lado se habían lanzado las precandidaturas de Ademar Pereira de Barros, gobernador de San Pablo, Kubitscheck y Lacerda para las elecciones presidenciales de 1965.

Pocos días más tarde «O Estado de São Paulo» consideraba inconstitucional el decreto de expropiación de tierras que había firmado Goulart que formaba parte de las llamadas reformas de base anunciadas en 1962. Eso hizo que se enfrentara a los poderes fácticos, representados por la oposición en el Congreso y por los gobernadores de varios estados (especialmente Lacerda de Guanabara; José Magalhaes Pinto, de Minas Gerais y de Barros de San Pablo), sectores empresariales - la prensa entre ellos - y de la clase media, propietarios rurales, la Iglesia y también grupos de la Justicia, temerosos todos de la "izquierdización" que le adjudicaban al gobierno y a pesar de que sus intereses corporativos no siempre eran coincidentes ${ }^{32}$. La situación económica tampoco colaboró. Cuando, dentro del Ejército, cobró fuerza el llamado movimiento de los sargentos, la estructura militar crujió porque vio amenazada su propia cadena de mandos.

Las reformas de base estaban vinculadas - entre otras - a la reforma agraria con la expropiación de campos de más de 600 hectáreas, más impuestos a las rentas financieras y exigencias tributarias a las empresas multinacionales instaladas en el Brasil y reformas electorales para permitir el voto de analfabetos, acompañadas de

${ }^{31}$ O Estado de São Paulo, 11 de marzo de 1964.

${ }^{2}$ RAMÍREZ, Hernán, «El golpe de Estado de 1964 en Brasil desde una perspectiva socio política», in op. cit., p. 258. 
medidas en salud y educación, las que habían sido precedidas por un acercamiento político a las posiciones del bloque soviético. Además, comprendían reforma bancaria, tributaria, administrativa y urbana (la única que no fue enviada al Congreso).

En marzo de 1964 la Fundación Getúlio Vargas alertaba desde su revista mensual «Conjuntura Econômica» que las finanzas públicas enfrentaban perspectivas desfavorables para ese año. Se señalaba, sin embargo, que si el gobierno controlaba efectivamente el gasto público (acababa de ser concedido un sustancial aumento de salarios al personal del Estado federal) y contenía tanto el desequilibrio fiscal como el déficit de caja del Tesoro Nacional, la emisión de papel moneda podía ser menor que en 196333. El gobierno era acusado de no encontrar soluciones a la situación económica y financiera del país, palpable - según los diarios - en los altos índices inflacionarios y la pérdida de reservas en moneda extranjera. El costo de vida orilló los 20 puntos en los primeros meses de 1964 tanto en San Pablo como en Río de Janeiro. A nivel nacional la inflación fue de 19,87 \% en enero, 22,10 \% en febrero y 23,64 \% en marzo 34 .

En lo que respecta a las tasas de cambio, para febrero de 1964, cuando el gobierno de Goulart desdobló la operatoria, el dólar se cotizaba a 620 cruzeiros por unidad en el mercado oficial y entre 1.160 y 1.200 cruzeiros en el mercado libre bajo control gubernamental. Pero donde más se sentían las turbulencias políticas era en el mercado paralelo, en el que el dólar llegó a superar los 2.000 cruzeiros en las agitadas jornadas previas al golpe (bajó a 1.420 cruzeiros por dólar en la primera semana de abril, ya instalado el gobierno militar). A medida que se acentuaba la "fuga" de divisas aumentaba la cotización del dólar y en marzo de 1964 la moneda nacional brasileña se depreció un 25\%. Con todo, la principal preocupación era la situación política, porque según se veía desde los sectores conservadores y se expresaba a través de los periódicos existía el riesgo cierto de una "cubanización” de Brasil.

\section{Un punto de no retorno}

Los acontecimientos se desarrollaron vertiginosamente desde mediados de marzo de 1964. El día 13, delante de unas 250 mil personas que se reunieron para escucharlo en la Estación Central de Río de Janeiro35, Goulart - que poco antes había firmado el decreto que abría definitivamente el camino hacia la reforma agraria y otro que

33 Conjuntura Econômica, XVIII, 3/1964,.

34 Conjuntura Econômica, XVIII, 4/1964.

35 Entre la multitud había unos 5 mil integrantes del ejército, portando banderas rojas, véase:

Correio da Manhã, 14 de marzo de 1964. 
expropiaba las refinerías petroleras - anunció su intención de luchar por una reforma constitucional ya que «nenhuma força será capaz de impedir que o governo continue a assegurar absoluta liberdade ao povo brasileiro. E para isto poderemos declarar, com orgulho, que contamos com a compreensão e o patriotismo das Forças Armadas» 36 .

«Folha de São Paulo» tituló que Goulart había sorprendido al país con la expropiación de las refinerías y en su página editorial se preguntaba por qué se había convocado al comicio de Río de Janeiro, al que entendía por un lado como un meeting de pre-dictadura y por otro como el lanzamiento de la reelección de Goulart, para lo cual era necesario reformar la Constitución. Concluía con un encubierto llamado a las Fuerzas Armadas ${ }^{37}$. El discurso presidencial provocó el malestar de parlamentarios y políticos opositores, el de la prensa conservadora ${ }^{38}$ y también alertó a la alta oficialidad militar, muchos de cuyos principales cuadros actuaban en el Club Militar y el Club Naval.

El 19 de marzo, se organizó en San Pablo la denominada Marcha da Família com Deus pela Liberdade39 bajo el pretexto que Goulart encaminaba a Brasil hacia el comunismo. Ese mismo día, «Jornal do Brasil» publicó unas "históricas” declaraciones del expresidente Dutra - que rompía un silencio de 13 años - en las que pedía respeto por la Constitución y la necesidad de la unidad mientras que llamaba a defender el régimen democrático mientras hubiera tiempo para hacerlo ${ }^{40}$.

«O Globo» le dedicó un amplio espacio en su primera página a la marcha paulista con un título que fijaba posición: «San Pablo de pie en defensa de la democracia» mientras que para «O Estado de São Paulo» y «Jornal do Brasil», en la marcha de San

\footnotetext{
${ }^{36}$ «Goulart decreta a desapropiação de terras, encampa refinarias e pede nova Constituição», in Jornal do Brasil, 14 de marzo de 1964; «Iniciado o Processo de Encampação das rafinarias além de assinado o Decreto desapropriador da SUPRA», in O Globo, 14 de marzo de 1964. La SUPRA era la Superintendencia de Política Agraria y el decreto declaraba de interés para fines sociales la expropiación de los terrenos aledaños a las redes ferroviarias, los lechos de las vías férreas nacionales y las tierras beneficiadas o recuperadas con obras nacionales de irrigación que estuvieran en ese momento sin explotación. El texto del decreto es disponible en URL: < http://brasilrepublicano.com.br/fontes/9.pdf > [consultado el 12 de septiembre de 2013]. 37 Folha de Sao Paulo, 14 de marzo de 1964.

38 «O discurso de Goulart no comício totalitario», in O Estado de São Paulo, 14 de marzo de 1964.

39 En la convocatoria de la Marcha participaron entidades de mujeres, varias de ellas vinculadas con la asistencia caritativa a los enfermos, desvalidos o desamparados, centros juveniles universitarios, instituciones profesionales como las de ingenieros o abogados, grupos definidos como anticomunistas o defensores de la democracia y asociaciones cristianas, entre otras, todas del estado de San Pablo. Ver la lista completa en O Estado de São Paulo, 17 de marzo de 1964. Los días subsiguientes hubo marchas similares en otras ciudades. 40 «A voz do soldado», in Jornal do Brasil, 19 de marzo de 1964.
} 
Pablo hubo medio millón de manifestantes «en contra del comunismo y la dictadura» ${ }^{4}$. El diario paulista habitualmente dedicaba su primera página a las informaciones internacionales, pero ese día la reservó casi la mitad de la tapa (con una gran foto) a la cobertura de la marcha y varias páginas interiores, en una de las cuales replicaba las consignas de los manifestantes: «Verde e amarelo, sem foice e sem martelo» 42 .

Al día siguiente de la Marcha da Família, «O Estado de São Paulo» citaba declaraciones del diputado Brízola que propugnaba «la democratización de la prensa» y que los diarios fueran entregados «a los partidos políticos»43. Sobre la prensa escrita pendía, por otra parte, la amenaza de una regulación oficial de la cuota que se exportaba de papel que correspondía a cada diario y la monopolización estatal de dicho mercado. «Jornal do Brasil» titulaba con la advertencia al presidente Goulart de parte de Magalhaes Pinto, gobernador de Minas Gerais: «una revolución desde arriba no es otra cosa que un golpe» contra las reglas democráticas»44.

A fines de marzo, durante la Semana Santa, se produjo otra rebelión de sargentos, marineros y fuzileiros navales, encabezada por el cabo José Anselmo45 que se atrincheraron y resistieron en el Sindicato de los Metalúrgicos, situación que desembocó en la renuncia del ministro de Marina Almirante Silvio Mota, quien había pretendido sin éxito reprimir la insurrección y su sustitución por el Almirante Paulo Mário da Cunha Rodrigues, que decidió no sancionar a los insubordinados ${ }^{46}$. El motín de los marineros acentuó la desconfianza de los sectores políticos y militares más opuestos a Goulart, que pedían el respeto de las jerarquías y el orden institucionales. Por un lado, los editoriales de los diarios daban a conocer su punto de vista sobre que el Ejecutivo parecía encaminarse hacia el desgobierno y la ilegalidad. Los almirantes denunciaron "la comunización" de Brasil47 y el club Militar emitió un duro comunicado en repudio de la insurrección ${ }^{48}$. El 30 de marzo, Goulart pronunció un discurso en el Automóvil Club de Brasil ante unos dos mil subtenientes y sargentos de las Fuerzas

${ }^{41}$ O Globo, 20 de marzo de 1964; «Enquanto há liberdade», in O Estado de São Paulo, 20 de marzo de 1964; «Passeata de 500 mil en São Paulo defende o regime», in Jornal do Brasil, 20 de marzo de 1964.

${ }^{42} \mathrm{O}$ Estado de São Paulo, 20 de marzo de 1964.

43 O Estado de São Paulo, 21 de marzo de 1964.

44 Jornal do Brasil, 21 de marzo de 1964.

45 Años después una investigación periodística reveló que Anselmo era informante de la Marina y la policía política antes del golpe contra Goulart, "Açao de Anselmo é pré-64, diz policial», Folha de Sao Paulo, 31 de agosto de 2009.

46 «Crise termina na Marinha com una morte, nôvo Ministro e amotinados en liberdade», in Jornal do Brasil, 28 de marzo de 1964. Por la gravedad de los acontecimientos el diario circuló igual, con una edición extraordinaria, a pesar de ser Sábado Santo, cuando habitualmente los periódicos no aparecían.

47 Jornal do Brasil, 30 de marzo de 1964.

48 O Globo, O Estado de São Paulo y Jornal do Brasil, 30 de marzo de 1964. 
Armadas a los que prometió un nuevo régimen de promoción. Para quienes estaban enfrentados con el Presidente, Jango hacía explícito su giro al izquierdismo. Era un punto de no retorno.

El 31 de marzo de 1964 «Correio da Manhã» publicó un durísimo editorial, titulado «Basta!» en el que anticipaba lo que sucedería ese mismo día. El matutino carioca ${ }^{49}$ se preguntaba hasta qué punto el Presidente abusaría de la confianza de la Nación y provocaría la desesperación de la clase media y de los trabajadores a través de la inflación y el costo de vida. Calificaba como «calamitosa» y una «farsa» a la situación que se vivía ${ }^{\circ}$. También el 31 de marzo «Jornal do Brasil» decía en primera página: «A disciplina facciosa nao vingará no Brasil, que já protesta em Minas Gerais, unido contra ela» 51 .

El último día de marzo, el general Olympio Mourao Filho, jefe del II Cuerpo de Ejército, desencadenó el golpe e hizo que sus tropas marcharan desde Minas Gerais a Río de Janeiro. Esa misma noche fuzilerios que respondían al almirante Aragao y que formaban parte del dispositivo militar de Jango, ocuparon el edificio de «O Globo» e impidieron que el diario imprimiera su edición con las noticias del golpe. Por eso, el día 2, el matutino publicó el editorial que no había visto la luz y que era una justificación de la acción militar ${ }^{2}$. Algo similar ocurrió en las instalaciones de «Jornal do Brasil» cuando tropas leales al Presidente pretendieron ocuparlas. Radio Jornal do Brasil, ante la disyuntiva de sumarse a la red oficial del gobierno de Goulart o dejar de emitir sus noticieros, eligió esta última opción, es decir eligió apoyar el golpe.

En un primer momento Goulart pensó en resistir con el apoyo de algunas guarniciones que él creía fieles, pero no era así. En la jornada del 1 de abril, el general Kruel adhirió a la rebelión y lo hizo «con el objetivo de salvar a la Patria en peligro, librándola del yugo rojo». Hacía referencia, además, al motín de los marineros, apoyados por almirantes «nítidamente de izquierdas» y llamaba la atención sobre la acción del Partido Comunista al interior de las Fuerzas Armadas, para inducirlas «a la indisciplina y división»53. El 2 de abril el Congreso destituyó a Goulart, quien cruzó la frontera hacia Uruguay dos días después. Simultáneamente, las Fuerzas Armadas

\footnotetext{
49 Así se conoce a los nativos de Río de Janeiro.

50 Correio da Manhã, 31 de marzo de 1964. El texto completo en URL:

< http://brasilrepublicano.com.br/fontes/38.pdf > [consultado el 21 de octubre de 2015].

51 «Reincidência», Jornal do Brasil, 31 de marzo de 1964. Ese día, la coluna de Castello se tituló: «Minas desencadeia luta contra Jango». Se refería a la advertencia ya citada del gobernador Magalhaes Pinto, pero resulta sugestivo, porque simultáneamente el golpe contra Goulart se ponía en marcha en Minas Gerais.

52 «A decisao da Pátria», in O Globo, 2 de abril de 1964.

53 La proclama de Kruel, entre otros, en O Estado de São Paulo, 1 de abril de 1964 («Kruel: contra o comunismo o movimento de Sao Paulo») y O Globo, 2 de abril de 1964.
} 
brasileñas se hicieron con el poder y pronto desataron la represión sobre los sectores, mayoritariamente de izquierda, que apoyaban a Jango y que, eventualmente, podían estar en condiciones de gestar algún tipo de oposición, como por ejemplo las Ligas Camponesas.

\section{Se establece el gobierno militar}

El golpe fue recibido con alivio en Washington. La amenaza comunista había sido el principal argumento para derrocar a Goulart. El gobierno de Estados Unidos reconoció rápidamente al régimen militar. En su edición del 2 de abril «O Globo» informaba que Goulart había huído y la democracia reestablecida, y señalaba «Vive a Nação dias gloriosos porque [...] gracias a decisao e ao heroismo das Fôrças Armadas que obedientes a seus chefes demostraran a falta de visao dos que tentavan destruir a hierarquia e a disciplina, o Brasil livran-se do govêrno irresponsável, que insistia en arrastá-lo para rumos contràrios a sua vocação e tradiçoes» y recordaba lo dicho un par de días antes con respecto a que la defensa de la legalidad no suponía garantizar la subversión. Señalaba, además, que no había sido un movimiento partidario, ya que en la acción militar habían participado todos los sectores "conscientes" de la vida política brasileña ${ }^{54}$.

También el 2 de abril, «Jornal do Brasil» informaba sobre detenciones de políticos y sindicalistas, además de enfrentamientos entre estudiantes y policías en Río de Janeiro, con el saldo de muertos y heridos y un atentado contra el diario «Última Hora» al que se le atribuían vínculos con sectores considerados varguistas y cuyo edificio fue atacado con bombas incendiarias por grupos de manifestantes partidarios de Lacerda ${ }^{55}$.

Ese día 2 de abril hubo manifestaciones multitudinarias en Río de Janeiro para celebrar la caída de Goulart. «O Globo» se refirió a «una impresionante masa humana de 800 mil personas» en la denominada Marcha de la Victoria (convocada de modo similar a la del 19 de marzo en San Pablo) y también le reclamó al Congreso que no decepcionara a los demócratas y no incurriera en errores «que pueden servir a los comunistas en desbandada». Enumeraba una serie de acciones que debía realizar el

54 O Globo, 2 de abril de 1964.

55 BARBOSA, Marialva, História cultural da imprensa: Brasil, 19oo-20oo, Río de Janeiro, Mauad X, 2007, pp. 168-169. "Última Hora» fue un diario de Río de Janeiro - primero vespertino y luego también matutino -, que nació en 1951 para apoyar al gobierno constitucional de Getúlio Vargas. y que era propiedad de Samuel Wainer, de quien Lacerda era enemigo declarado. «Última Hora» fue uno de los pocos medios que apoyó a Goulart. 
Parlamento: completar la tarea iniciada por los militares, "limpiar" la adm inistración federal y el campo sindical de elementos comunistas, sancionar una Ley de Defensa del Estado, regular el derecho de huelga y legislar sobre la cuestión agraria «tratada con liviandad y deshonestidad» por el gobierno depuesto ${ }^{56}$.

El 4 de abril Goulart se exilió en Uruguay y el 11 de abril asumió como primer presidente de la flamante dictadura el general Humberto de Castelo Branco, tenentista en los '20, golpista en los '6o, «elemento identificado con los más altos objetivos de la revolución»57. Obtuvo 361 de los 438 votos en el Colegio Electoral. Tiempo después, João Belchior Marques Goulart (con sus derechos políticos suspendidos por el Acta Institucional Nro. 1.) se radicó en la provincia de Corrientes, Argentina, donde murió el 6 de diciembre de 1976 a los 58 años, 12 de ellos pasados en el exilio: aún hoy se buscan elementos que prueben que su muerte fue una de las primeras acciones de la llamada Operación Cóndor, de cooperación entre los gobiernos militares que detentaban el poder en el Cono Sur.

\section{A modo de conclusión preliminar}

¿Qué llevó al poderoso e influyente «O Globo» a reconocer como equivocada una posición asumida hacía casi cincuenta años? En principio, lejos de pensar hoy en el «socorro de la Providencia divina», como decía su editorial del día posterior al golpe contra Goulart, atribuyó su giro discursivo a una reacción empresaria por los cánticos de los manifestantes en las marchas que se dieron por todo Brasil en junio de 2013, los que dieron cuenta del apoyo del medio a la dictadura. Pero la vinculación de «O Globo» y otros diarios con el golpe que terminó con la experiencia de Goulart no es algo que se descubre ahora. Se ha escrito y dicho bastante mucho antes de «la voz de la calle que merece ser escuchada», como el diario sostuvo en 2013.

En su viaje al pasado «Última Hora» incorporó a varios compañeros de ruta, como diarios muy influyentes, entonces y ahora, aunque algunos ya no existen. También recordó el apoyo que una parte de la sociedad brasileña brindó a la intervención militar. Es decir, en su reconocimiento de culpas hubo espacio para muchos matices. Para realizar este trabajo partimos desde otro punto de abordaje. ¿De qué se arrepintió «O Globo» en 2013?

El régimen militar brasileño que nació en 1964 se extendió por más de dos décadas y si bien permitió el funcionamiento del Congreso y la realización periódica de 
elecciones, condicionó y limitó fuertemente la actividad político partidaria. Y fue bajo las normas fijadas por la dictadura brasileña que se negociaron los términos de la transición hacia la democracia en 1985. Para ese entonces, los medios que tan abiertamente apoyaron la irrupción en el poder por parte de las Fuerzas Armadas ya habían tomado distancia del régimen. En 1964, «O Globo» jugó a favor de lo que llamó "revolución", porque - contradictoriamente - supuso que la interrupción de la vida constitucional era el salvoconducto para mantener vigente la democracia. Creyó, como «Folha de São Paulo» en las promesas hechas por los militares en el sentido de respetar el calendario electoral que preveía, para 1966, elecciones presidenciales. «O Globo» se refirió a la acción militar en términos elogiosos y transfirió las mayores responsabilidades por el quiebre institucional al gobierno depuesto y a los sectores vinculados a él. En ese aspecto, los oficiales brasileños inauguraron la primera dictadura institucional del Cono Sur y establecieron un "manual de estilo" para los golpes en toda la región.

En este estudio hemos recreado las principales argumentaciones a favor del golpe de los medios periodísticos más enfrentados a Goulart (abiertamente opositores a los intentos de reformas sociales, económicas y políticas de su gobierno) y visibilizamos con claridad cómo contribuyeron esos diarios a la formación de una nueva alianza de los sectores dominantes, bloque de poder que pronto mostró sus acotados márgenes de maniobra en un mundo entonces dominado por el conflicto Este/Oeste, como lo demuestran las referencias a la "amenaza comunista" o el temor a la "cubanización" de Brasil. 


\section{* El autor}

Julio Héctor Macías es licenciado en Historia por la Universidad Nacional de Mar del Plata y además es periodista, con actuación en medios escritos, radiales y televisivos. Académicamente se desempeña en la cátedra de Historia Americana Contemporánea de la Universidad Nacional de Mar del Plata (UNMdP). Sus objetos de estudio son (en ambos casos para la América Latina) la relación de los medios de comunicación con el poder y la gravitación social de los deportes, especialmente el fútbol.

URL: < http://www.studistorici.com/progett/autori/\#Macias >

\section{Per citare questo articolo:}

MACÍAS, Julio Héctor, «Arrepentimientos, olvidos y silencios. Nueva lectura del apoyo periodístico al golpe de estado de 1964 en Brasil», Diacronie. Studi di Storia Contemporanea : Le dittature militari: fisionomia ed eredità politica, 29/12/2015,

URL:< http://www.studistorici.com/2015/12/29/macias_numero_24/ >

Diacronie Studi di Storia Contemporanea $\beta$ www.diacronie.it

Risorsa digitale indipendente a carattere storiografico. Uscita trimestrale. redazione.diacronie@hotmail.it

Comitato di redazione: Jacopo Bassi - Luca Bufarale - Elisa Grandi - Antonio César Moreno Cantano - Deborah Paci - Fausto Pietrancosta - Alessandro Salvador - Matteo Tomasoni - Luca Zuccolo

Diritti: gli articoli di Diacronie. Studi di Storia Contemporanea sono pubblicati sotto licenza Creative Commons 3.0. Possono essere riprodotti e modificati a patto di indicare eventuali modifiche dei contenuti, di riconoscere la paternità dell'opera e di condividerla allo stesso modo. La citazione di estratti è comunque sempre autorizzata, nei limiti previsti dalla legge. 